\title{
Extended Definition of Capacity in Airport Systems
}

\author{
Miguel Mujica Mota and Geert Boosten \\ Aviation Academy, Amsterdam University of Applied Sciences, The Netherlands
}

\begin{abstract}
Nowadays the main airports throughout the world are suffering because their capacity are getting close to saturation due to the air traffic which is still increasing besides the economic crisis and oil prices. In addition, the forecasts predict an increase in air traffic of at least 3.6\% until 2020. This situation makes very important to come up with solutions to alleviate capacity congestions in the main airports throughout the world. Capacity has been perceived traditionally as the factor to be addressed in airport systems and it is faced through a technical perspective. In this paper we propose to change the mind-set and view capacity of airport systems taking other factors than pure technical ones. The discussion is illustrated with the example of Schiphol Airport.
\end{abstract}

Keywords: Airport, Aviation, Capacity, Mismatch, System

\section{INTRODUCTION}

Nowadays the main airports throughout the world are suffering because their capacity are getting close to saturation due to the air traffic which is still increasing besides the economic crisis and oil prices ${ }^{1}$. In addition, the forecasts predict an increase in air traffic of at least 3.6\% until 2020². Furthermore in the case of European Airports, it has been reported that around 60 European airports are at the edge of congestion. The latter statement is based on the declared capacity of the airports which most of the time calculate their number based on the technical characteristics present in airports. These levels of saturation will be perceived in the coming years as problems in different functional areas at the airport itself. At the airside more and more aircrafts will be put on holding, delays incurred due to lack of gates after landings, congestions in the terminals and in general queues everywhere at different levels.

Traditionally capacity problems have been seen and addressed from the technical stand point. Assuming that the operations within an airport are a mixture of parallel and sequential operations the practical capacity can be defined in terms on the most restricted element of the airport ${ }^{3}$. Furthermore, depending of the airport system under study, the bottleneck can change and will direct in most of the time the actions to be taken in order to cope with the current demand. If the airport is not able to handle in the proper way the passengers then an expansion of the terminal will be planned; on the other hand if the schedule flights incur in more delays that a particular threshold then it would suggest that the problem is on the capacity of the runway system, thus a new runway could be the solution for the

1 EUROCONTROL, 2008,"Challenges of Growth”, <http:www.eurocontrol.int/articles/challenges-growth

2 Airport Council International, 2004, "Study on the Use of Airport Capacity", ACI EUROPE, pp. 1-15, Brussels, Belgium

3 Janic, M., 2008,"Airport Analysis, Planning and Design”, NOVA, New York 
capacity constraint and so on. Adding a new runway is a long-lasting process; therefore various studies indicate that in most of the cases runway capacity (defined in number of hourly movements) is the limiting factor for airport capacity ${ }^{4}$. Other studies indicate that airport capacity is a more complex matter that involves various different factors. Suau-Sanchez ${ }^{6}$ et al. mention that the total airport capacity is the aggregate of infrastructure capacity, air space capacity and environmental capacity. Wei et al. ${ }^{7}$ argue that congested hub capacity will have up- and downstream effects on spoke capacity as well. These studies show that there is no single definition of airport capacity and that various factors play a role.

Defining airport capacity by maximum hourly runway movements does not cover all the limiting elements. Other factors that also play a role in the capacity must be taken into account such as societal restrictions and airline business models on hub and spokes. These restrictions are sometimes subjective but it does not mean that must be neglected under a decision-making process. Elements like noise, emissions but also limited runway slots all influence the possible solutions to deal with constraint airports on how to allocate airport capacity amongst airport users or what measures will add capacity to the airport on the long run.

In order to better understand the elements that influence the airport capacity and study the possible solutions on how to deal with constraints airports an extended airport capacity definition is needed.

In the following sections the different factors that must be taken into account are presented and discussed, and an extended definition of capacity is addressed.

\section{THE CAPACITY EQUATION}

As it has been mentioned before, the capacity has been traditionally defined based on the technical elements that allow the flow of entities within the airports such as time slots, runways, facilities to handle the incoming traffic and passengers. This paradigm of analysing the system is the correct one under the assumption that the system depends on these solely factors and on the interrelationships among them. However it is important to keep in mind that airports have different roles and functions. The main function of an airport is not only to transport people and goods (or to connect air- and land transportation); nowadays the functions of the airport have evolved to more complex airport cities. They can have a strategic role for the development of regions; they provide connection at regional and at global level that in turn impact the development of society. The allocation of airport capacity amongst airlines is important for the role and contribution of the airport for the region. In some studies this is referred to as the bringing airport demand management measures in the allocation of scarce airport slots ${ }^{8}$. In addition to these functions, there is a close interaction between the airline business model (i.e. how to operate the hub and spoke model) and the use of airport capacity in the hub-and-spoke system.

Besides the economic roles the aviation is playing within a region, it has been perceived that in developed countries people are actively involved in the operation of airports (directly or indirectly). Society not only appreciate airport benefits, but can also be annoyed by airport hinders (noise, emission, etc.); thus society in turn can have a preponderant role in the operation limits of an airport. This role can be more or less important depending on the development of the country and the society itself. Noise is not a technical issue but requires a societal response and community participation to handle. If this is not done properly society can have a large influence on limiting the airports capacity. Suau-Sanchez et al. ${ }^{9}$ define therefore environmental capacity as: 'the level of airport operational ability that can be reached after airport activity is limited due to socio-environmental factors.' .

4 Desart, B., Gillingwater D., Janic, M., 2010, "Capacity dynamics and the formulation of the airport capacity/stability paradox: A European perspective",Journal of Air transport Management Volume 16, Issue 2, pp. 81-85

5 Wilken, D., Berster, P., Gelhausen, M., 2011,"New empirical evidence on airport capacity utilisation: Relationship between hourly and annual traffic volumes. Research in Tranpor-tation Business \& Mangement", Vol.1, Issue 1, pp. 188-127

6 Suau-Snachez, P., Pallares-Barbera, M., Paül, V. 2011, "Incorporating annoyance in airport environmental policy: noise, societal response and community participation”, Journal of Transport Geography, Vol.19, Issue 2, pp. 275-284

7 Wei, W., Hansen, M., 2006,"An aggregate demand model for air passenger traffic in the hub-and-spoke-network", Transportation Research Part A: Policy and Practice, Volume 40 Issue 10, pp. 841-851

8 Madas, M., Zografos,K., 2010, “Airport slot allocation: a time for change? Transport Poli-cy”, Vol. 17, Issue 4, pp. 274-285

9 Suau-Snachez, P., Pallares-Barbera, M., Paül, V. 2011, "Incorporating annoyance in airport environmental policy: noise, societal response and community participation”, Journal of Transport Geography, Vol.19, Issue 2, pp. 275-284 
The extended role of the airport in case of constraint capacity requires not only the efficient use of the existing capacity by the current users. The society demands an optimal balance of the airport added value for the region and the hinder caused by the airport operations. Any unbalance will in future further hamper the development of airport capacity.

The purpose of this article is come up with an extended equation of airport capacity that includes the various elements that together define the airport capacity. Each of these elements can have a different set of variables to define the impact on the airport capacity and to manage the possible solutions to extend the capacity in future.

\section{PARAMETERS OF THE EQUATION}

The different elements of the capacity equation (1) must be discussed in order to understand the role they play in the system.

\section{CAPACITY: F(Business Model, infrastructure, airspace, societal conditions) (1)}

Business model. The business model determines how the airlines serve the different markets of interest. Traditionally the business model has influenced the operation of airports in different regions of the world basically through the development of their networks ${ }^{10}$. The airports adapt their operation and facilities in accordance with the business model of the airlines that are the direct client of the airports. In some airports the operations are strongly influenced by the legacy carrier within the region of the airport which is the leader in the local market. Thus the airport operation is directly influenced by the relationships between the most influential actors and the airport itself.

Infrastructure. Infrastructure is the most known and studied of the parameters that choke capacity in airports. As it has been discussed, the scientific community pays a lot of attention in ways of managing in a more efficient way

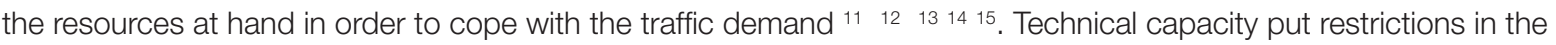
available facilities but on the other hand capacity restrictions can be the driver for developing novel techniques that force the evolution of the industry e.g. optimization techniques, more efficient engines etc.

Airspace. The airspace is the region (3D) in the air in which the airplanes are flown. This space is basically controlled by humans with the support of technology such as radars, GPS, satellites. Since the activity of monitoring and controlling the flying entities is performed by humans, there are inherent risks and limits to the control operations. Due to the increase in traffic the international community is looking for innovative ways to manage the flow of aircraft within the airspace in order to reduce conflicts and improve the flight plans ${ }^{16}{ }^{17}$.

Societal Conditions. This parameter of the equation might have been not important some years ago; but with the evolution of societies this factor is getting more importance since society is having more influence in the developments needed to cope with the demand of the coming years. There are some interesting examples that give evidence of the role that this factor is having nowadays ${ }^{18}$.

10 Airport Council International, 2004, "Study on the Use of Airport Capacity", ACI EUROPE, pp. 1-15, Brussels, Belgium

11 Arias, P.,Guimarans, D., Mujica, M., Boosten G., 2013,"A methodology combining opti-mization and simulation for real applications of the Stochastic Aircraft Recovery Problem", in Proc. of EUROSIM 2013, Cardiff, UK.

12 Mujica, M., Zuniga, C., 2013, "A Simulation-Evolutionary Approach for the allocation of Check-In Desks in Aiport Terminals", in Proc. of ATOS 2013, Tolouse, France

13 Solak, S., Clarke J.B., Johnson, E.L., 2009, "Airport terminal capacity planning”, Trans-portation Research Part B, Elsevier

14 Madas, M., Zografos,K., 2010, “Airport slot allocation: a time for change? Transport Poli-cy”, Vol. 17, Issue 4, pp. $274-285$

15 Wilken, D., Berster, P., Gelhausen, M., 2011,"New empirical evidence on airport capacity utilisation: Relationship between hourly and annual traffic volumes. Research in Tranpor-tation Business \& Mangement", Vol.1, Issue 1, pp. 188-127

16 SESAR JU, <http://ec.europa.eu/transport/modes/air/sesar/index_en.htm>

17 NextGen, www.faa.gov/nextgen/.../NextGen_Implementation_Plan_2013.pdf

18 Suau-Sanchez, P., Pallares-Barbera, M., Paül, V. 2011, "Incorporating annoyance in airport environmental policy: noise, societal response and community participation”, Journal of Transport Geography, Vol.19, Issue 2, pp. 275-284 


\section{SCHIPHOL AIRPORT CASE}

Schiphol is a good case to illustrate both the extended importance of the airport for the region (the so-called mainport impact) as well as that fact that the airport is constraint by both runway limitations (maximum hourly movements) and societal constraints in terms of noise. Finding the balance between added value (mainport and hinder) is a key issue for Schiphol and therefore understanding the building blocks of capacity in order to manage the balancing act.

Schiphol currently performs 425,000 operations which corresponds to an $83.3 \%$ of saturation considering the declared capacity of 510,000 ATM $^{19}$. For all these reasons the national government is interested in developing a system of airports that serve for the purpose of the region. Fig. 1 illustrates the region in which the new system is planned to operate. The local government is concerned about the capacity levels that Schiphol has reached thus they propose to develop an airport system in which some traffic will be diverted from Schiphol to regional airports. Currently local and regional actors are struggling to devise what will be the best way and which traffic to divert and the implications and consequences for the region under those decisions.

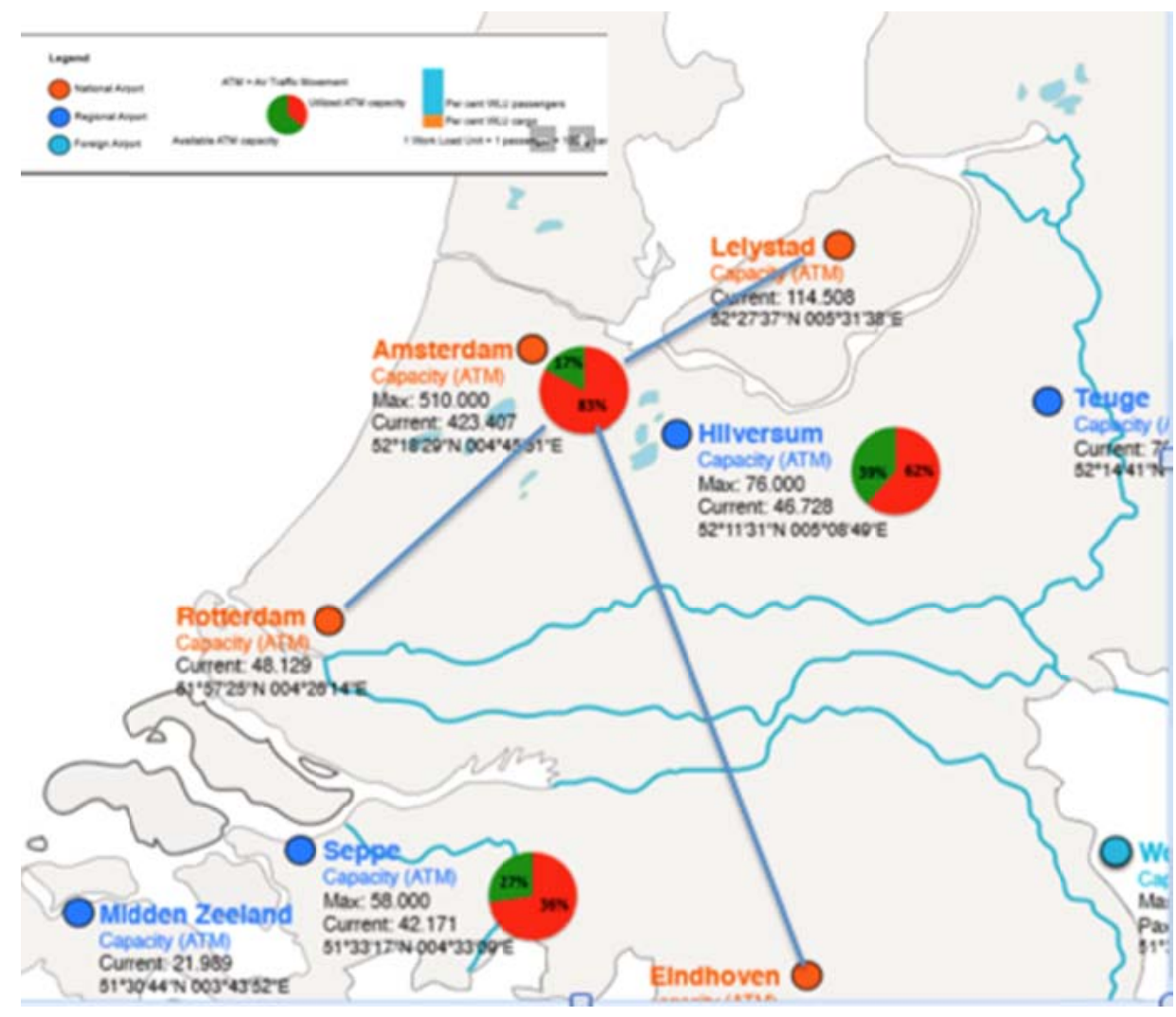

\section{Figure. 1. The situation of North Holland}

Schiphol airport has a declared capacity of 510,000 ATM/year ${ }^{20}$. On 2012 the number of ATM reached 423,407 which corresponded to a level of saturation of $83 \%$. This numbers represent an increase compared to the previous year in which the ATM numbers reached 420,349 ATM as Fig. 2 illustrates.

19 Schiphol Airport, 2011,"Feiten en Cijfers”, <http:Schiphol.nl/SchipholGroup1>

20 Ministry of Infrastructre and Environment, 2009, "BIJlage1 Luchvaartnota", <http://www.rijksoverheid.nl/> 


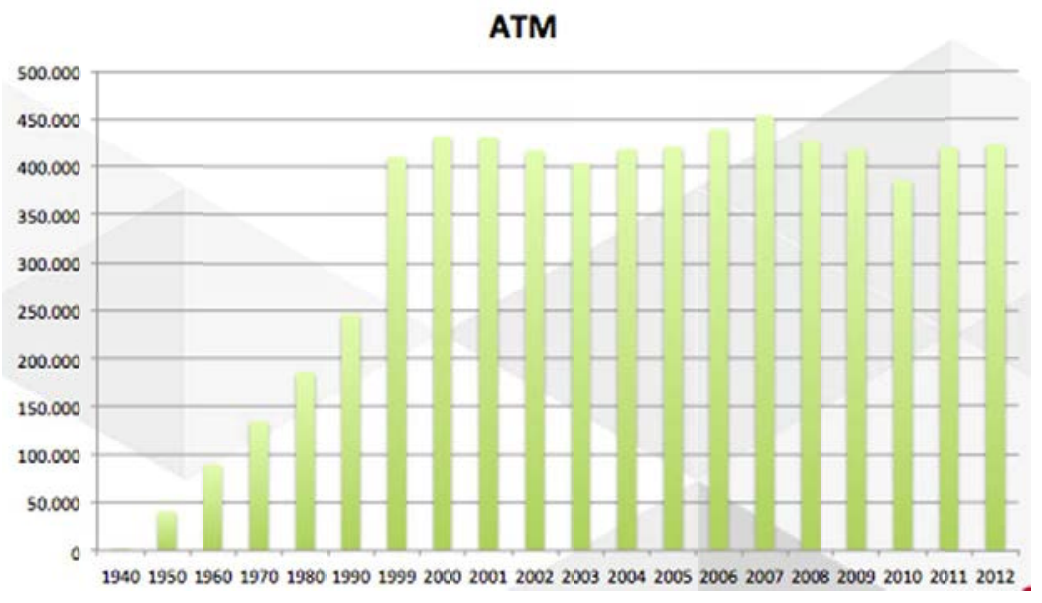

\section{Figure. 2. Traffic evolution in Schiphol}

According to what has been investigated by different authors ${ }^{21}{ }^{22}$ with these numbers one would be expected to perceive high queues or more delays in the airport. On the contrary Schiphol has been improved in terms of delay figures. During 2012 according to EUROCONTROL average delay per flight was reduced in 10\% compared to $2011^{23}$. The previous numbers indicate that at least in the case of Schiphol there is a mismatch between technical capacity and the actual capacity.

\section{The Capacity Equation for Schiphol}

The different elements will be discussed in this subsection to illustrate that the capacity equation should be investigated in order to come up with a more elaborated definition of capacity that can be applied to different airports.

\section{Business Model}

Schiphol is strongly influenced by the legacy carrier KLM with his partner AF. The main hub of KLM-AF is Schiphol airport. They belong to the Skyteam alliance. The business model operated by KLM has put a lot of pressure to the local government to keep the alliance partners inside Schiphol and those who are not considered of value be diverted to the secondary airports in the future system. Under these assumptions Schiphol must adapt to the type of traffic that will appear under this model and the necessary adaptations must be performed for that objective.

\section{Infrastructure}

Schiphol is a large airport with 5 runways and huge terminal facilities. In terms of operations it has a good performance as it suggests their numbers in punctuality (measured as $15 \mathrm{~min}$. tolerance). In the case of arrivals it went from $86.1 \%$ to $87.6 \%$ in punctuality and for departures it went from $81.2 \%$ to $81.9 \%$ both evaluated from 2012 to $2013^{24}$; this numbers are surprising since during 2013 the traffic increased and one would expect that the delays would increase as well if it were the case of a congested airport.

\section{Airspace}

The airspace indeed chokes capacity but in the case of Schiphol TMA has been improved as the delay figures suggest ${ }^{25}$. Besides that one of the main objectives of the SESAR is to increase airspace capacity through the socalled $4 \mathrm{D}$ trajectories ${ }^{26}$.

21 Janic, M., 2008,"Airport Analysis, Planning and Design”, NOVA, New York

22 Solak, S., Clarke J.B., Johnson, E.L., 2009, "Airport terminal capacity planning”, Trans-portation Research Part B, Elsevier

23 EUROCONTROL, 2012, "Delays to Airtransport in Europe", CODA Digest ANNUAL <http://www.eurocontrol.int/sites/default/files/ content/documents/official-documents/>

24 Schiphol Group, 2013, "Facts and Figures" <http://www.schiphol.nl/SchipholGroup/Company1/Statistics/FactsFigures.htm>

25 Schiphol Group, 2013, "Facts and Figures" <http://www.schiphol.nl/SchipholGroup/Company1/Statistics/FactsFigures.htm>

26 SESAR JU, <http://ec.europa.eu/transport/modes/air/sesar/index_en.htm> 


\section{Societal Conditions}

Netherlands is developed country in which the function of the airport is taken for granted and the region counts on the airport as another transport mode as efficient as the train or car. The efficiency of this transport mode must be achieved under a regulated environment. The airport must ensure not only the technical rules inherent to these kinds of systems such as (separation rules, crosswind rules, etc.) but also new restrictions imposed by the society. In the case of Schiphol these relationship with society is materialized in the Alders Platform which is "a consultative body in which the government, the aviation sector, local authorities and residents make agreements aimed at ensuring the aviation activities at Schiphol and the quality of life in the region remain in equilibrium" ${ }^{27}$. This Alders platform has the objective to put into play the interest of society when decisions concerned to the airport facility are being evaluated. During 2013 the Alders agreement influenced strongly the operation of the airport in such a way that the airport needed to adapt itself in order to avoid exceeding the noise limits in the vicinity of the airport measured with the noise enforcement points. This is just a small example of how society is acquiring more impact in the operation of such a facility and must be taken into account for the evaluation of capacity.

\section{CONCLUSIONS}

Due to the increase in traffic worldwide, focus has been put in the capacity of air-ports throughout the world; in particular, in the case of Europe and the developed countries some factors have come into scene. These factors have been discussed in the paper and the case of Schiphol is presented to illustrate that there are different factors (some old but other new) that affect the actual capacity of a facility. The numbers presented contradict the expected performance when the traffic is increased thus suggesting that capacity is constrained by a different factors than the technical ones. The challenge for the scientific community is to investigate the different factors that influence nowadays modern aviation if good decisions are being taken for facing the future demand.

27 Schiphol Group, 2013, "Annual Report 2013", <http://www.annualreportschiphol.com/our-results/sustainable-performance/noise-andthe-local-community\#> 